Rosniawaty, S. • R. Sudirja $\cdot$ H. Hidayat

\title{
Pemanfaatan limbah organik sebagai media tanam dan aplikası urin ternak pada pembibitan kopi (Coffea arabica 1.)
}

\section{The use of organic waste as media planting and application of cattle urine for coffee (Coffea arabica 1.) seedlings}

Diterima : 15 Februari 2017/Disetujui : 15 Maret 2017 / Dipublikasikan : 30 Maret 2017

CDepartment of Crop Science, Padjadjaran University

\begin{abstract}
Coffee production depends on the initial cultivation. Nursery is one of stages of cultivation to produce good seedling and will produce high yield. Media planting and fertilization is one of the important things in producing good seedling. Coffee pericarp and leaves waste is used as planting media and adding of rabbit urine and cow urine was expected to produced good coffee seedlings. The experiments have been conducted on FebruaryMay 2014 at The Balai Pengembangan Benih Tanaman Perkebunan (BPBTP) Sindanglaya Bandung. The treatments used were a combination of media using compost leaves or coffee pericarp with rabbit urine concentration, or the concentration of cow urine. Rabbit urine or cow urin fermented before used. Urine concentration of rabbit and cow were 25\%. The experimental design used was a randomized block design, there were 10 treatment and repeated 3 times. The results showed that soil and compost of pericarp of coffee (2: 1 or 3: 1) as media and rabbits urine affected on plant height, stem diameter and number of leaves. Soil and compost leaves (3: 1) media and rabbit urine have the best effect both of the root volume and leaf area. Media soil: compost coffee pericarp (2: 1) and Cow urine effect only on the variables plant height
\end{abstract}

Keywords: Coffee $\cdot$ Cow urine $\cdot$ Rabbit urine

Sari Produksi kopi ditentukan mulai dari awal pembudidayaannya. Pembibitan merupakan salah satu tahapan budidaya untuk menghasilkan bibit yang baik dan dapat menghasilkan

Dikomunikasikan oleh Fiky Yulianto Wicaksono

Rosniawaty, S. $^{1} \cdot$ R. Sudirja ${ }^{1} \cdot$ H. Hidayat ${ }^{2}$

Program Studi Agroteknologi Fakultas Pertanian Unpad

Jl. Raya Bandung Sumedang, km-21 Jatinangor

Korespondensi: santi.rosniawaty@unpad.ac.id tanaman yang berproduksi tinggi. Media tanam dan pemupukan merupakan salah satu hal penting dalam menghasilkan bibit yang baik. Pemanfaatan limbah kulit buah kopi dan serasah daun sebagai campuran media tanam serta penambahan urin kelinci dan urin sapi diharapkan dapat menghasilkan bibit kopi yang baik. Percobaan telah di laksanakan pada bulan Februari-Mei 2014. Percobaan dilaksanakan di Balai Pengembangan Benih Tanaman Perkebunan (BPBTP) Sindanglaya Bandung Perlakuan yang digunakan adalah kombinasi antara media menggunakan kompos daun atau kompos kulit kopi dengan konsentrasi urin kelinci, atau konsentrasi urin sapi. Urin kelinci atau urin sapi difermentasikan terlebih dahulu sebelum digunakan. Konsentrasi urin kelinci atau urin sapi sebesar $25 \%$. Rancangan percobaan yang digunakan adalah Rancangan Acak Kelompok, terdapat 10 perlakuan yang di ulang 3 kali. Hasil percobaan menunjukkan bahwa media tanah dan kompos kulit kopi (2:1 ataupun 3:1) dan urin kelinci berpengaruh paling baik pada tinggi tanaman, diameter batang dan jumlah daun. Media tanah dan kompos daun (3:1) dan urin kelinci berpengaruh paling baik pada volume akar dan luas daun. Media tanah : kompos kulit buah kopi (2:1) dan Urin sapi hanya berpengaruh pada variabel tinggi tanaman.

Kata kunci: Kopi · Urine sapi · Urine kelinci

\section{Pendahuluan}

Indonesia merupakan salah satu negara penghasil kopi. Indonesia mampu memproduksi kopi sebanyak 675,8 ribu ton dengan luas lahan 1,24 juta pada tahun 2013 (Direktorat Jendral Perkebunan, 2014). Pengembangan industri pengolahan kopi di dalam negeri memiliki prospek yang sangat baik, 
mengingat konsumsi kopi masyarakat Indonesia rata-rata baru mencapai $1,2 \mathrm{Kg}$ perkapita/tahun dibanding dengan negara-negara pengimpor kopi seperti Amerika Serikat 4,3 Kg, Jepang 3,4 Kg, Austria 7,6 Kg, Belgia 8,0 Kg, Norwegia 10,6 Kg dan Finlandia 11,4 Kg perkapita/tahun (Hartono, 2013)

Produktivitas tanaman kopi di Indonesia masih rendah yaitu baru mencapai $700 \mathrm{Kg}$ biji kopi/ha/tahun untuk Robusta dan $800 \mathrm{Kg}$ biji kopi/ha/Tahun untuk Arabika, sedangkan produktivitas negara Vietnam telah mencapai lebih dari $1.500 \mathrm{Kg} / \mathrm{ha} /$ tahun (Hartono, 2013). Namun demikian Indonesia memiliki kopi yang khas yang sesuai dengan kondisi lingkungan tertentu seperti kopi arabika Java Preanger dari Jawa Barat.

Peningkatan produktivitas dapat dilakukan sejak pembibitan. Masa pembibitan merupakan masa yang penting dalam pertumbuhan kopi. Bibit yang baik akan menghasilkan buah kopi yang banyak. Pertumbuhan bibit yang baik dipengaruhi oleh media tanam yang digunakan. Media tanam pembibitan tanaman perkebunan pada umumnya menggunakan bahan organik disamping tanah. Media tumbuh bibit kopi pada pembibitan merupakan campuran tanah lapisan atas, pasir yang halus dan pupuk kandang (1:1:1) tergantung dari kondisi tanahnya (Rahardjo, 2013).

Bahan organik yang dapat digunakan berupa kompos. Kompos dapat berasal dari sisa daun-daun ataupun memanfaatkan limbah organik yang ada disekitar pembibitan. Limbah kulit kopi merupakan salah satu bahan organik yang dapat digunakan sebagai media tanam pembibitan kopi. Kelebihan kulit buah kopi yang telah dikomposkan sebagai media tanam pembibitan adalah unsur hara yang terserap saat pembentukan buah kopi sebagian dapat dikembalikan dan digunakan kembali oleh tanaman kopi.

Media tanam yang baik harus diikuti dengan pemeliharaan selama pembibitan. Salah satu tindakan pemeliharaan yang baik adalah pemupukan. Umumnya pupuk yang digunakan adalah pupuk anorganik. Penggunaan pupuk anorganik secara terus menerus akan menyebabkan kerusakan fisik pada tanah. Perlu dicari alternatif pupuk yang dapat diperoleh dengan mudah, tidak mengganggu lingkungan dan pengaruhnya baik untuk pertumbuhan bibit kopi.

Alternatif pupuk yang dapat digunakan adalah urin kelinci dan urin sapi. Kelinci dan sapi merupakan hewan peliharaan yang dapat menghasilkan urin setiap harinya. Urin merupakan limbah dari hewan, sehingga apabila tidak dimanfaatkan dapat mencemari lingkungan. Sapi akan lebih banyak menghasilkan urin apabila dibandingkan dengan kelinci, urin kelinci memiliki kelebihan dibandingkan dengan urin sapi. Hasil penelitian Rinekso dkk (2011) urin sapi asal Jatibarang yang telah difermentasi selama 15 hari mengadung $\mathrm{C}$ organik 4,49\%, N 0,7\%, P 0,16\%, K 0,62\% serta C/N 6,41. Berdasarkan hasil penelitian Badan PenelitianTernak (Balitnak) tahun 2005 dikutip Setyanto,dkk (2014), kotoran urine kelinci memiliki kandungan unsur $\mathrm{N}, \mathrm{P}, \mathrm{K}$ yang lebih tinggi $(2,72 \%, 1,1 \%$, dan $0,5 \%)$ dibandingkan dengan kotoran dan urine ternak lainnya seperti kuda, kerbau, sapi, domba, babi dan ayam.

Beberapa penelitian menunjukan adanya pengaruh yang baik dari penggunaan urin kelinci dan urin sapi. Hasil penelitian Oliveira, dkk (2009) aplikasi urin sapi 1,25\% ke daun dan $1 \%$ ke tanah direkomendasikan untuk tanaman lettuce (Lactuca sativa). Hasil penelitian Nugraheni dan Paiman (2010) pada tanaman tomat bahwa konsentrasi urin kelinci 3000 ppm dapat meningkatkan pertumbuhan vegetatif tanaman yaitu berat segar tanaman, berat kering tanaman, berat kering daun dan berat kering batang, tetapi tidak berpengaruh pada pertumbuhan generatif tanaman. Hasil penelitian Rosniawaty, dkk (2015) bahwa terdapat pengaruh penggunaan urin kelinci dan urin sapi yang telah difermentasi terhadap luas daun, volume akar dan bobot kering bibit kakao pada umur 16 minggu setelah tanam (mst). Penggunaan urin sapi dengan konsentrasi 25\% dapat menyamai penggunaan pupuk anorganik pada pembibitan kakao.

Penelitian penggunaan urin kelinci dan urin sapi yang telah difermentasi pada pembibitan tanaman perkebunan masih perlu dilakukan. Oleh karena itu perlu dilakukan penelitian aplikasi urin kelinci dan urin sapi yang telah difermentasi pada pembibitan kopi.

\section{Bahan dan Metode}

Percobaan dilaksanakan di Balai Pengembangan Benih Tanaman Perkebunan (BPBTP) Sindanglaya Bandung. Tempat percobaan terletak pada ketinggian $\pm 788 \mathrm{~m}$ di atas permukaan laut. Percobaan dilakukan dari bulan Februari 2014 
sampai dengan bulan Mei 2014. Berdasarkan klasifikasi Schmidt dan Fergusson (1951), lokasi percobaan memiliki tipe curah hujan $\mathrm{C}$

Bahan-bahan yang digunakan dalam percobaan adalah bibit kopi klon Lini S-795 berumur $17 \mathrm{mst}$ dari BPBTP Sindanglaya Bandung, urin kelinci dan urin sapi dari peternakan Unpad yang difermentasi (konsentrasi 25 $\%$, kompos kulit kopi, kompos daun, tanah lapisan atas (top soil) Andisol dari Lembang, paranet $60 \%$, polibeg ukuran $20 \times 25$, EM4 sebagai dekomposer, tali rapia, bambu, paku, dan pestisida. Alat yang digunakan pada percobaan ini adalah cangkul, embrat, jangka sorong, oven, penggaris, meteran, gelas ukur $1.000 \mathrm{~mL}$, timbangan analitik, label, gunting, palu, termometer, dan alat tulis.

Rancangan percobaan yang digunakan adalah rancangan acak kelompok dengan 10 perlakuan yang diulang 3 kali. Adapun perlakuan yang diberikan adalah sebagai berikut:

$$
\begin{aligned}
\mathrm{A}= & \text { Tanah }: \text { Kompos Daun }(2: 1) \\
\mathrm{B}= & \text { Tanah }: \text { Kompos Daun }(2: 1)+\text { Urea } \\
& \text { 2g/polibeg } \\
\mathrm{C}= & \text { Tanah }: \text { Kompos Daun }(2: 1)+\text { Urin Kelinci } \\
\mathrm{D}= & \text { Tanah }: \text { Kompos Daun }(3: 1)+\text { Urin Kelinci } \\
\mathrm{E}= & \text { Tanah }: \text { Kompos Kulit Kopi }(2: 1)+\text { Urin } \\
& \text { Kelinci } \\
\mathrm{F}= & \text { Tanah }: \text { Kompos Kulit Kopi }(3: 1)+\text { Urin } \\
& \text { Kelinci } \\
\mathrm{G}= & \text { Tanah }: \text { Kompos Daun }(2: 1)+\text { Urin Sapi } \\
\mathrm{H}= & \text { Tanah : Kompos Daun }(3: 1)+\text { Urin Sapi } \\
\mathrm{I}= & \text { Tanah : Kompos Kulit Kopi }(2: 1)+\text { Urin } \\
& \text { Sapi } \\
\mathrm{J}= & \text { Tanah : Kompos Kulit Kopi }(3: 1)+\text { Urin } \\
& \text { Sapi }
\end{aligned}
$$

Analisis statistik untuk mengetahui pengaruh perlakuan dengan menggunakan uji Fischer, apabila signifikan, dilanjutkan dengan uji Duncan pada taraf kepercayaan 95\%.

\section{Hasil dan Pembahasan}

Data curah hujan memperlihatkan bahwa pada bulan Februari rata-rata curah hujan 1,67 $\mathrm{mm} /$ hari, pada bulan Maret dengan rata-rata curah hujan 17,84 mm/hari, pada bulan April dengan rata-rata curah hujan 10,68 mm/hari, dan pada bulan Mei dengan rata-rata curah hujan $0,09 \mathrm{~mm} /$ hari. Temperatur udara rata-rata selama percobaan dari bulan Februari sampai dengan Mei berkisar antara 23,5-24,3 ${ }^{\circ} \mathrm{C}$.
Kelembaban udara rata-rata pada bulan Februari sampai dengan Mei berkisar antara 75,8 -

\begin{tabular}{|c|c|c|}
\hline Jenis Analisis & $\begin{array}{c}\text { Kompos } \\
\text { Daun }\end{array}$ & $\begin{array}{c}\text { Kompos Kulit } \\
\text { Kopi }\end{array}$ \\
\hline N-Total (\%) & 0,50 & 0,49 \\
\hline $\mathrm{P}_{2} \mathrm{O}_{5}(\%)$ & 0,23 & 0,77 \\
\hline $\mathrm{K}_{2} \mathrm{O}(\%)$ & 0,13 & 0,04 \\
\hline $\mathrm{C} / \mathrm{N}$ & 15 & 14 \\
\hline C-org & 7,45 & 6,96 \\
\hline $\mathrm{pH} \mathrm{H} \mathrm{H}_{2} \mathrm{O}$ & 7,57 & 7,35 \\
\hline $\mathrm{pH} \mathrm{KCl}$ & 7,18 & 6,97 \\
\hline Kadar Air & 62,14 & 73,45 \\
\hline
\end{tabular}
$86,3 \%$. Curah hujan yang sesuai untuk kopi seyogyanya adalah $1500-2500 \mathrm{~mm}$ per tahun, dengan rata-rata bulan kering 1-3 bulan dan suhu rata-rata 15-25 derajat celcius (Puslitkoka, 2006 dikutip Prastowo, dkk 2010). Berdasarkan hasil analisis curah hujan dan temperatur udara selama percobaan, menunjukan kondisi lingkungan yang mendukung untuk pertumbuhan bibit kopi.

Tabel 1. Perbandingan Hasil Analisis Urin Sapi, dan Urin Kelinci yang telah difermentasikan

\begin{tabular}{ccc}
\hline \hline Jenis Analisis & Urin Kelinci & Urin Sapi baru \\
\hline$p H$ & 7,07 & 8,25 \\
$\mathrm{~N}$-total (\%) & 0,14 & 0,81 \\
$\mathrm{P}_{2} \mathrm{O}_{5}(\%)$ & 0,12 & 0,12 \\
$\mathrm{~K}_{2} \mathrm{O}(\%)$ & 0,61 & 0,98 \\
\hline \hline
\end{tabular}

Tabel 2. Perbandingan Hasil Analisis Hara Kompos Daun dan Kompos Kulit Kopi

Hasil analisis di laboratorium Kesuburan Tanah dan Nutrisi Tanaman Faperta Unpad, urin kelinci dan urin sapi yang telah difermentasi tercantum pada Tabel 1. Hasil analisis urin menunjukkan bahwa urin sapi mempunyai kandungan hara yang lebih tinggi daripada urin kelinci, kecuali pada kandungan $\mathrm{P}_{2} \mathrm{O}_{5}$ yang kadarnya sama dengan urin kelinci. Namun $\mathrm{pH}$ urin kelinci mendekati netral, sehingga membantu penyerapan unsur hara. Hasil analisis kompos daun dan kompos kulit kopi tercantum pada Tabel 2. Kompos kulit kopi memiliki kandungan $\mathrm{P}_{2} \mathrm{O}_{5}$ dan kadar air lebih tinggi dibandingkan kompos daun.

Tinggi Tanaman. Berdasarkan hasil analisis statistik yang tercantum pada Tabel 3 perlakuan I (Tanah : Kompos Kulit Kopi (2:1) + Urin Sapi) memberikan tinggi tanaman tertinggi dibandingkan dengan perlakuan lainnya pada setiap umur pengamatan. Namun pada umur 12 minggu setelah aplikasi (msa) perlakuan I 
tingginya sama dengan perlakuan $\mathrm{D}, \mathrm{E}, \mathrm{F}$. yaitu Tanah : kompos daun (2:1) dan tanah kompos kulit kopi (2:1) dan (3:1) semuanya menggunakan urin kelinci. Hal ini dapat disebabkan oleh kandungan $\mathrm{P}_{2} \mathrm{O}_{5}$ yang sama antara urin kelinci dan urin sapi yaitu $0,12 \%$. Kompos kulit kopi juga memiliki $\mathrm{P}_{2} \mathrm{O}_{5}$ yang tinggi dibandingkan dengan kompos daun, sehingga penggunaan kompos kulit kopi (3:1) mampu menyamai penggunaan kompos daun (2:1). Unsur $P$ berperan dalam pembelahan sel dan pembentukan jaringan baru serta sebagai sumber energi pada metabolisme tanaman. Unsur $\mathrm{P}$ juga merupakan elemen kunci yang berpengaruh besar pada pembentukan dan pertumbuhan perakaran (Abdolzadeh, et al 2010). Pertumbuhan akar yang baik akan mampu menyerap unsur hara dengan optimal, sehingga berpengaruh pada pertumbuhan batang (tinggi tanaman).

Tabel 3. Rata-Rata Tinggi Tanaman pada Umur 4,8 dan $12 \mathrm{msa}$

\begin{tabular}{clcc}
\hline \hline \multirow{2}{*}{$\begin{array}{c}\text { Perla- } \\
\text { kuan }\end{array}$} & \multicolumn{3}{c}{ Tinggi Tanaman $(\mathrm{Cm})$} \\
\cline { 2 - 4 } $\mathrm{A}$ & $4 \mathrm{msa}$ & $8 \mathrm{msa}$ & $12 \mathrm{msa}$ \\
$\mathrm{B}$ & $2.57 \mathrm{a}$ & $3.00 \mathrm{ab}$ & $6.76 \mathrm{~A}$ \\
$\mathrm{C}$ & $2.91 \mathrm{abc}$ & $5.38 \mathrm{~b}$ & $13.87 \mathrm{~B}$ \\
$\mathrm{D}$ & $3.65 \mathrm{bcde}$ & $7.88 \mathrm{cc}$ & $16.58 \mathrm{bc}$ \\
$\mathrm{E}$ & $4.11 \mathrm{bcdef}$ & $8.54 \mathrm{def}$ & $19.12 \mathrm{D}$ \\
$\mathrm{F}$ & $5.03 \mathrm{ef}$ & $10.14 \mathrm{df}$ & $20.16 \mathrm{D}$ \\
$\mathrm{G}$ & $4.81 \mathrm{def}$ & $7.78 \mathrm{~cd}$ & $15.89 \mathrm{bc}$ \\
$\mathrm{H}$ & $3.29 \mathrm{bcd}$ & $7.33 \mathrm{bcd}$ & $17.80 \mathrm{~cd}$ \\
$\mathrm{I}$ & $5.35 \mathrm{f}$ & $10.36 \mathrm{f}$ & $20.25 \mathrm{D}$ \\
$\mathrm{J}$ & $4.41 \mathrm{cdef}$ & $8.91 \mathrm{def}$ & $19.26 \mathrm{~cd}$ \\
\hline \hline
\end{tabular}

Keterangan : Angka yang diikuti huruf yang sama pada kolom yang sama, tidak berbeda nyata menurut uji Duncan taraf kepercayaan 95\%

Diameter Batang. Hasil analisis statistik terhadap diameter batang tercantum pada Tabel 4. Perlakuan E ( Tanah : Kompos Kulit Kopi (2:1) + Urin Kelinci ) mempunyai diameter lebih besar dibandingkan perlakuan lain pada umur 8 msa. Pada umur 12 msa perlakuan F ( Tanah : Kompos Kulit Kopi (3:1) + Urin Kelinci) dapat menyamai perlakuan $\mathrm{E}$ dalam hal diameter batang. Kompos kulit kopi yang sedikit lambat berpengaruh terhadap pertumbuhan diameter batang. Seperti halnya pada tinggi tanaman, unsur P yang terdapat pada kompos kulit kopi dan urin kelinci mempengaruhi pertumbuhan diameter batang. Unsur P sebagai komponen koenzim, fosfoipid dan asam nukleat (Taiz dan
Zeiger, 2006) yang mempengaruhi pembelahan sel sehingga berpengaruh besar dalam proses pebelahan sel.

Tabel 4. Rata-Rata Diameter Batang pada Umur 4,8 dan $12 \mathrm{msa}$

\begin{tabular}{cccc}
\hline \hline Perla- & \multicolumn{3}{c}{ Diameter Batang $(\mathrm{cm})$} \\
\cline { 2 - 4 } kuan & $4 \mathrm{msa}$ & $8 \mathrm{msa}$ & $12 \mathrm{msa}$ \\
\hline $\mathrm{A}$ & 0.04 & $0.09 \mathrm{a}$ & $0.11 \mathrm{a}$ \\
$\mathrm{B}$ & 0.04 & $0.08 \mathrm{a}$ & $0.13 \mathrm{ab}$ \\
$\mathrm{C}$ & 0.04 & $0.10 \mathrm{a}$ & $0.15 \mathrm{ab}$ \\
$\mathrm{D}$ & 0.06 & $0.09 \mathrm{a}$ & $0.16 \mathrm{bc}$ \\
$\mathrm{E}$ & 0.06 & $0.13 \mathrm{~b}$ & $0.19 \mathrm{c}$ \\
$\mathrm{F}$ & 0.05 & $0.11 \mathrm{ab}$ & $0.20 \mathrm{c}$ \\
$\mathrm{G}$ & 0.05 & $0.07 \mathrm{a}$ & $0.13 \mathrm{ab}$ \\
$\mathrm{H}$ & 0.03 & $0.08 \mathrm{a}$ & $0.14 \mathrm{ab}$ \\
$\mathrm{I}$ & 0.04 & $0.07 \mathrm{a}$ & $0.14 \mathrm{ab}$ \\
$\mathrm{J}$ & 0.04 & $0.09 \mathrm{a}$ & $0.17 \mathrm{bc}$ \\
\hline \hline
\end{tabular}

Keterangan : Angka yang diikuti huruf yang sama pada kolom yang sama, tidak berbeda nyata menurut uji Duncan taraf kepercayaan 95\%

Tabel 5. Rata-Rata Jumlah Daun pada Umur 4,8 dan 12 msa

\begin{tabular}{cccl}
\hline \hline \multirow{2}{*}{ Perlakuan } & \multicolumn{3}{c}{ Jumlah Daun (helai) } \\
\cline { 2 - 4 } & $4 \mathrm{msa}$ & $8 \mathrm{msa}$ & $12 \mathrm{msa}$ \\
\hline $\mathrm{A}$ & 1.00 & 1.08 & $1.42 \mathrm{a}$ \\
$\mathrm{B}$ & 1.17 & 1.58 & $3.75 \mathrm{abcd}$ \\
$\mathrm{C}$ & 1.50 & 2.17 & $3.42 \mathrm{abc}$ \\
$\mathrm{D}$ & 1.50 & 2.42 & $5.75 \mathrm{bcd}$ \\
$\mathrm{E}$ & 2.50 & 3.33 & $6.00 \mathrm{~cd}$ \\
F & 2.08 & 3.00 & $6.42 \mathrm{~d}$ \\
$\mathrm{G}$ & 0.75 & 2.17 & $2.92 \mathrm{ab}$ \\
$\mathrm{H}$ & 0.83 & 2.50 & $4.92 \mathrm{bcd}$ \\
$\mathrm{I}$ & 1.08 & 2.83 & $5.67 \mathrm{bcd}$ \\
J & 1.33 & 2.92 & $5.42 \mathrm{bcd}$ \\
\hline \hline
\end{tabular}

Keterangan : Angka yang diikuti huruf yang sama pada kolom yang sama, tidak berbeda nyata menurut uji Duncan taraf kepercayaan 95\%

Jumlah Daun. Hasil analisis statistik pada Tabel 5 menunjukkan bahwa pengaruh perlakuan baru terlihat pada umur 12 msa. Perlakuan F (Tanah : Kompos Kulit Kopi (3:1) + Urin Kelinci ) memberikan jumlah daun lebih banyak dibandingkan dengan perlakuan $\mathrm{A}, \mathrm{C}$ dan $G$ tetapi sama dengan perlakuan lainnya. Kadar air kompos kulit kopi lebih tinggi dibandingkan dengan kompos daun, sehingga mampu menyediakan bahan fotosintesis lebih banyak. Hasil fotosintesis tersebut dapat digunakan untuk pertumbuhan daun Air juga berfungsi menjadikan hara dalam media menjadi tersedia dalam bentuk kation dan 
Tabel 6.Bobot Kering Akar, Volume Akar, Panjang Akar, Luas Daun dan Bobot Kering Bibit pada umur $12 \mathrm{msa}$

\begin{tabular}{cccccc}
\hline \hline Perlakuan & $\begin{array}{c}\text { Bobot Kering } \\
\text { Akar }(\mathrm{g})\end{array}$ & $\begin{array}{c}\text { Volume Akar } \\
(\mathrm{ml})\end{array}$ & $\begin{array}{c}\text { Panjang Akar } \\
(\mathrm{cm})\end{array}$ & $\begin{array}{c}\text { Luas Daun }(\mathrm{Cm} 2) \\
\text { Bobot Kering } \\
\text { Tanaman }(\mathrm{g})\end{array}$ \\
\hline $\mathrm{A}$ & 1.73 & $8.67 \mathrm{bcd}$ & 30.70 & $43.87 \mathrm{a}$ & 4.75 \\
$\mathrm{~B}$ & 2.08 & $8.00 \mathrm{bc}$ & 26.50 & $62.32 \mathrm{abc}$ & 7.70 \\
$\mathrm{C}$ & 2.19 & $10.67 \mathrm{~cd}$ & 31.07 & $77.75 \mathrm{bc}$ & 7.36 \\
$\mathrm{D}$ & 2.28 & $12.33 \mathrm{~d}$ & 28.97 & $80.56 \mathrm{c}$ & 10.23 \\
$\mathrm{E}$ & 2.33 & $8.67 \mathrm{bcd}$ & 37.50 & $73.49 \mathrm{bc}$ & 8.94 \\
$\mathrm{~F}$ & 1.93 & $8.33 \mathrm{bcd}$ & 27.97 & $69.80 \mathrm{bc}$ & 9.34 \\
$\mathrm{G}$ & 1.52 & $4.00 \mathrm{a}$ & 26.47 & $47.12 \mathrm{a}$ & 6.36 \\
$\mathrm{H}$ & 1.72 & $9.00 \mathrm{bcd}$ & 33.67 & $56.69 \mathrm{ab}$ & 7.47 \\
$\mathrm{I}$ & 2.14 & $6.00 \mathrm{ab}$ & 30.33 & $46.66 \mathrm{a}$ & 9.82 \\
$\mathrm{~J}$ & 1.89 & $5.67 \mathrm{ab}$ & 27.80 & $57.64 \mathrm{ab}$ & 8.17 \\
\hline \hline
\end{tabular}

anion. Kemasaman urin kelinci yang mendekati netral membuat unsur hara menjadi lebih tersedia untuk tanaman, sehingga unsur hara yang ada dapat digunakan bibit kopi untuk pembentukan daun. Perlakuan F tidak berbeda dengan perlakuan B yang artinya dapat menyamai penggunaan pupuk anorganik.

Bobot Kering Akar, Volume Akar, Panjang Akar, Luas Daun dan Bobot Kering Bibit. Hasil analisis statistik pada Tabel 6 menunjukan tidak terdapat pengaruh perlakuan terhadap bobot kering akar, volume akar dan bobot kering tanaman. Perbedaan signifikan terdapat pada volume akar dan luas daun. Perlakuan D (Tanah : Kompos Daun (3:1) + Urin Kelinci ) memiliki volume akar dan luas daun tertinggi. Hal ini dapat disebabkan kandungan $\mathrm{N}$ dan $\mathrm{K}$ yang tinggi pada kompos daun. Kedua unsur tersebut berperan dalam pembentukan klorofil dan mempertahankan turgor sel (Taiz dan Zeiger 2006). Dengan demikian luas daun menjadi lebih baik. Tekstur kompos daun diduga mampu menyebabkan pertumbuhan akar yang baik, sehingga volume akar menjadi besar.

\section{Kesimpulan dan Saran}

Kesimpulan :

1. Media tanah dan kompos kulit kopi (2:1 ataupun 3:1) dan urin kelinci berpengaruh paling baik pada tinggi tanaman, diameter batang dan jumlah daun

2. Media tanah dan kompos daun (3:1) dan urin kelinci berpengaruh paling baik pada volume akar dan luas daun
3. Media tanah : kompos kulit buah kopi (2:1) dan Urin sapi hanya berpengaruh baik pada variable tinggi tanaman .

Saran. Perlu dianalisis struktur dan kesuburan kimia media tanam saat akhir percobaan sehingga lebih jelas peranan kompos kulit buah kopi, kompos daun, urin sapi atau urin kelinci.

\section{Daftar Pustaka}

Abdolzadeh, A.' X. Wang, E. J. Veneklaas, ${ }^{2}$ and H Lambers ${ }^{2}$. 2010. Effects of phosphorus supply on growth, phosphate concentration and cluster-root formation in three Lupinus species. 2010 Mar; Annals of Botany. 105(3): 365-374. https://www.ncbi.nlm.nih.gov/ pmc/articles/PMC2826247/\#MCP297C30 diakses tanggal 1 Februari 2017

C de Oliveira, N.L., M. Puiatti, R. Henrique S Santos, P. R. Cecon and P. H. R. Rodrigues. 2009. Soil and leaf fertilization of lettuce crop with cow urine. Abstract. Hortic. Bras. vol.27 no.4 Brasília Oct./Dec. 2009. http://www.scielo.br/scielo.php Diakses tanggal 21 Februari 2015

Direktorat Jenderal Perkebunan. 2014. Statistik Perkebunan Indonesia (Kopi). Direktorat Jenderal Perkebunan.

Hartono. 2013 . Produksi Kopi Nusantara Ketiga Terbesar di Dunia. Siaran Pers http://www. kemenperin.go.id/artikel/6611/Produksi-KopiNusantara-Ketiga-Terbesar-Di-Dunia Diakses pada tanggal 24 Februari 2016

Nugraheni, E.D. dan Paiman. 2010 . Pengaruh Konsentrasi dan Frekunsi Pemberian Pupuk Urin Kelinci terhadap Pertumbuhan dan Hasil Tomat (Lycopersicum esculentum Mill) 
http://upy.ac.id/agroteknologi/files/PENGAR UH\%20KONSENTRASI\%20DAN\%20FREK UENSI\%20PEMBERIAN\%20PUPUK\%20U RIN\%20KELINCI\%20TERHADAP\%20PER TUMBUHAN\%20DAN\%20HASIL \%20TO MAT.pdf. Diakses pada tanggal 21 Februari 2015.

Prastowo B., E. Karmawati, Rubijo, Siswanto, C. Indrawanto, dan S. J. Munarso. 2010. Budidaya dan Pasca Panen Kopi. Pusat Penelitian Perkebunan. http:// perkebunan. litbang.pertanian.go.id/wp-content/ uploads/2012/08/perkebunan_budidaya_ kopi.pdf. Diakses tanggal 2 Februari 2017

Rahardjo, P. 2013. Kopi (Panduan Budidaya dan Pengolahan Kopi Arabika dan Robusta). Penebar Swadaya.

Rinekso K. B., E. Sutrisno, dan S. Sumiyati. 2011. Studi Pembuatan Pupuk Organik Cair dari Fermentasi Urine Sapi (Ferisa) dengan Variasi Lokasi Peternakan yang Berbeda.
eprints.undip.ac.id/42243/1/JURNAL.doc x. Diakses tanggal 21 Februari 2015

Rosniawaty, S., R. Sudirja dan H. Afrianto. 2015. Pemanfaatan Urin Kelinci dan Urin Sapi sebagai Alternatif Pupuk Organik Cair pada Pembibitan Kakao (Theobroma cacao L.). Jurnal Kultivasi. Volume 14 No 1. Maret 2015.

Schmidt, F.H. and J.H.A. Ferguson. 1951. Rainfall Thypes Based on Wet and Dry Period Ratios for Indonesian With Western Nem Duinee. Djulie. Bogor.

Setyanto,N.W. , L. Riawati dan R. P. Lukodono. 2014. Desain Eksperimen Taguchi untuk Meningkatkan Kualitas Pupuk Organik Berbahan Baku Kotoran Kelinci. JEMIS Vol. 2 No. 2 Tahun 2014. Published online at http://JEMIS.ub.ac.id/

Taiz, L. and E. Zeiger .2006. Plant Physiology. Sianuer Associates, Inc., Publisher. Sunderland, Massachussetts. 